\title{
Innovative Activity as a Means of Developing the Economic Potential of the Tourism Industry
}

\author{
Ismailov Adhambek Bakhramovich \\ Department of Tourism, Tourism and Economics Faculty, Urgench State University, Urgench City, Uzbekistan
}

Email address:

goodluck_0714@mail.ru

\section{To cite this article:}

Ismailov Adhambek Bakhramovich. Innovative Activity as a Means of Developing the Economic Potential of the Tourism Industry. Journal of Investment and Management. Vol. 7, No. 3, 2018, pp. 86-90. doi: 10.11648/j.jim.20180703.13

Received: June 25, 2018; Accepted: July 6, 2018; Published: August 6, 2018

\begin{abstract}
This article gives an overview of the peculiarities of the use of innovations in tourism and their role in improving the investment attractiveness of the tourism industry of the Republic of Uzbekistan. And also the article highlights different approaches of creating favorable investment conditions for the creation of innovative tourism products. In the article the role of tourism has been demonstrated in the development of regional economies and the current condition of tourism in the region is analyzed with different approaches and methods. Thus, the distinctive feature of the development of innovative activities in tourism from classical tourist activities is the creation of a new or improvement of the existing tourist product, the improvement of transport, hotel and other services, the development of new markets, the introduction of advanced information and telecommunications technologies and modern forms of organizational and managerial activity.
\end{abstract}

Keywords: Tourism, Innovation, Investment, Economics, Empowerment, Performance

\section{Introduction}

Innovation in the tourism industry is the creation of new tourist products using the achievements of science, IT technologies, as well as best practices in the areas of management and marketing, the result of which will increase employment, ensure the growth of its incomes, enhance socio-economic development and the tourist attraction capability of the country and regions. For the development of the tourism industry and related industries, the primary task of the state and business is to create favorable investment conditions for the creation of innovative tourism products. The Decree of the President of the Republic of Uzbekistan on $3^{\text {rd }}$ February, 2018-year "On additional organizational measures to create favorable conditions for the development of tourism potential of the Republic of Uzbekistan" was an important program for raising this work to a new level [1].

Nowadays, many strategic projects are implemented to accelerate the development of tourism in Uzbekistan. During the years of independence, tourism has become a dynamically developing sector of the national economy, with growth rates reaching $7.6 \%$ over the past 20 years. This indicator is much higher than the world tourism growth rate (4.5\%). In 2000 year 320000 foreign tourists visited
Uzbekistan, and in 2006 this figure increased 7.1 times and reached 2.16 million people. Nowadays tourism exports totaled 1.2 bln. dollars.

3.2 paragraph of the Strategy of Actions for the development of the Republic of Uzbekistan along five priority areas in 2017-2021 is about improving the competitiveness of the economy through deepening of structural reforms, modernization and diversification of its leading industries. There are two lines about tourism in the Concept:

1. Achieving accelerated development of the tourism industry, enhancing its role and contribution to the economy;

2. Diversification and improving the quality of tourist services, upgrading of tourism infrastructure.

Using the innovation technologies in the tourism sphere is key research among the present tourism and economics science scholars. We can see them in the work of Justyna M., Szymon T. [2] as Cluster-mapping procedure for tourism regions based on geostatistics and fuzzy clustering: example of Polish districts, Keith D. [3] Economic geographies of tourism: one 'turn' leads to another. Tourism Geographies. Their paper highlighted the importance of better knowledge management systems to support innovation in tourism. In their work, they mentioned that new ways of thinking and 
innovation in tourism is to argue that there is no such thing as sustainable tourism. There are also researcher who helped to develop the ideology on using innovations in tourism and sustainable tourism in various journals. Sofia K., Dimitris K., Thanasis K. [4], Justyna M. [5], Irma B., Christian M. Rogerson. [6], César C., Beatriz F., Montserrat B. [7], Katarzyna C. [8], Xiang Y., Merethe L., Hans O. [9], Ko K., Rhodri Th. [10].

According to them the basis of innovation in all sectors of the economy is the implementation of scientific and technological progress. The scientific and technological revolution not only became the material basis for the formation of mass tourism. It has had a tremendous impact on innovation in socio-cultural services and tourism through high technologies, including new materials, microprocessor

\section{CONSTANT 2016 UZSBN}

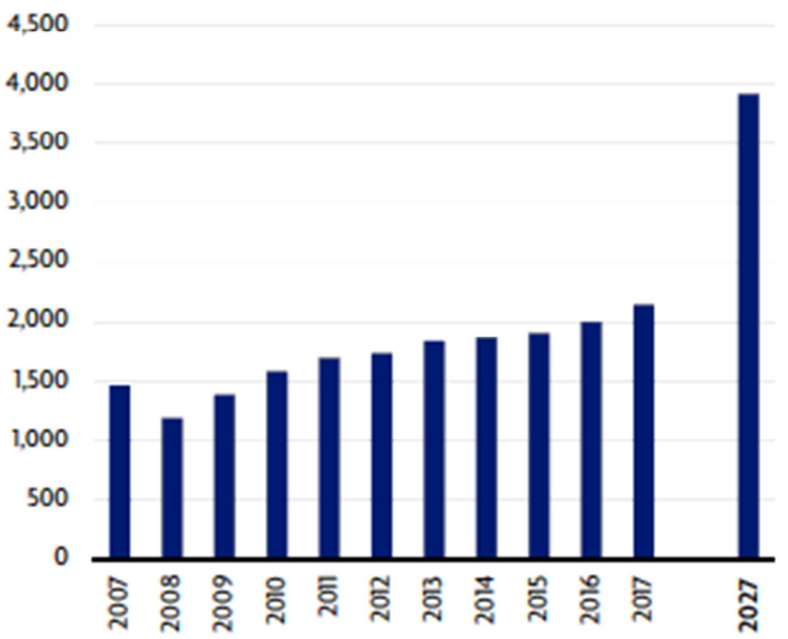

technology, media and communications, and biotechnology. Thus, innovative activity in the sphere of tourism is aimed at creating a new or changing existing product, improving transport, hotel and other services, developing new markets, introducing advanced information and telecommunication technologies and modern forms of organizational and managerial activity.

\section{Method}

The strategy of accelerated development of the tourism industry, its role and share in the economy, the diversification and quality of tourist services, the expansion of the tourism infrastructure and the Concept of tourism development have been specifically mentioned [11].

\section{$\%$ OF WHOLE ECONOMY GDP}

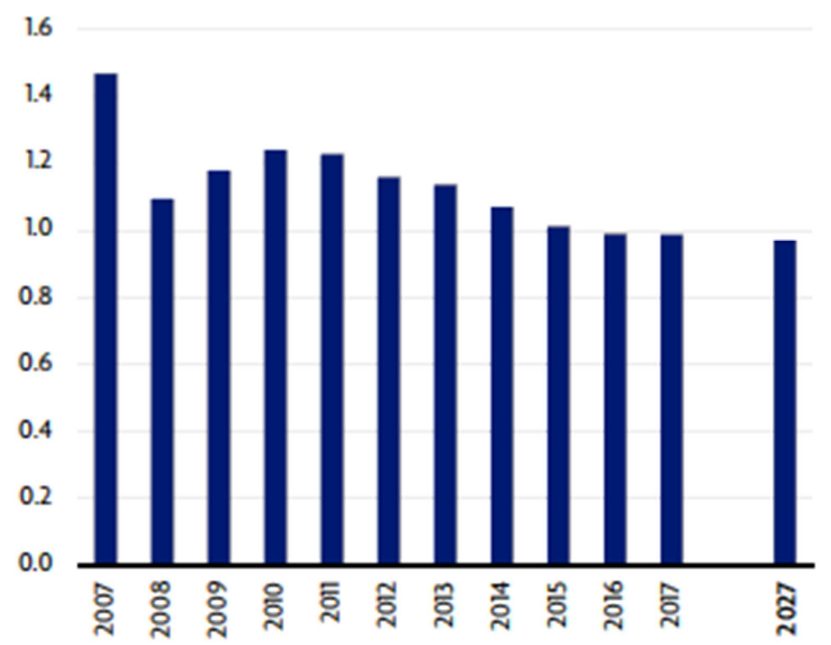

Figure 1. Uzbekistan: direct contribution of travel \& tourism to GDP [12].

The direct contribution of Travel \& Tourism to GDP in 2016 was $2,002.6$ bln UZS ( $1.0 \%$ of GDP). It was forecast to increase by $7.2 \%$ to $2,147.3$ bln UZS in 2017[12]. This primarily reflects the economic activity generated by industries such as hotels, travel agents, airlines and other passenger transportation services (excluding commuter services). But it also includes, for example, the activities of the restaurant and leisure industries directly supported by tourists.

The total contribution of Travel \& Tourism to GDP (including wider effects from investment, the supply chain and induced incomeimpacts, was UZS6,203.0bn in 2016 $(3.1 \%$ of GDP) and is expected to grow by $7.2 \%$ to UZS6,651.1bn (3.1\% of GDP) in 2017. It is forecast to rise by $6.2 \%$ pa toUZS $12,113.3$ bn by 2027 (3.0\% of GDP) [12].

Tourist organizations in a market economy are increasingly aware of the need to develop new products and services and related economic benefits. Due to its unique natural and cultural potential, as well as the huge interest of tourists from the far and near abroad as a new unreached direction, Uzbekistan has all the grounds for innovative development of the tourist industry.
The main directions of the formation of the national innovation system are stipulated in the policy of the Republic of Uzbekistan:

1. Creation of a favorable economic and legal environment (creation of a favorable investment climate);

2. Construction of innovative infrastructure;

3. Improvement of the organizational and economic mechanisms of state assistance to commercialize the results of research and experimental development.

In a market economy, innovations should contribute to the intensive development of the economy, accelerate the introduction of the latest achievements of science and technology in production, and more fully satisfy consumers in a variety of high-quality and competitive products and services. In recent decades, in most developed countries, the service sector has been growing at an accelerating rate, exceeding the growth in industrial production. Income from international tourism in 1999 amounted to 500 billion dollars, which is $12 \%$ of the world's gross product. By 2020 , tourism revenues will reach 3 trillion. US Dollars. In 40 countries, tourism is the main source of the budget, and in 70 countries - one of the three components. 


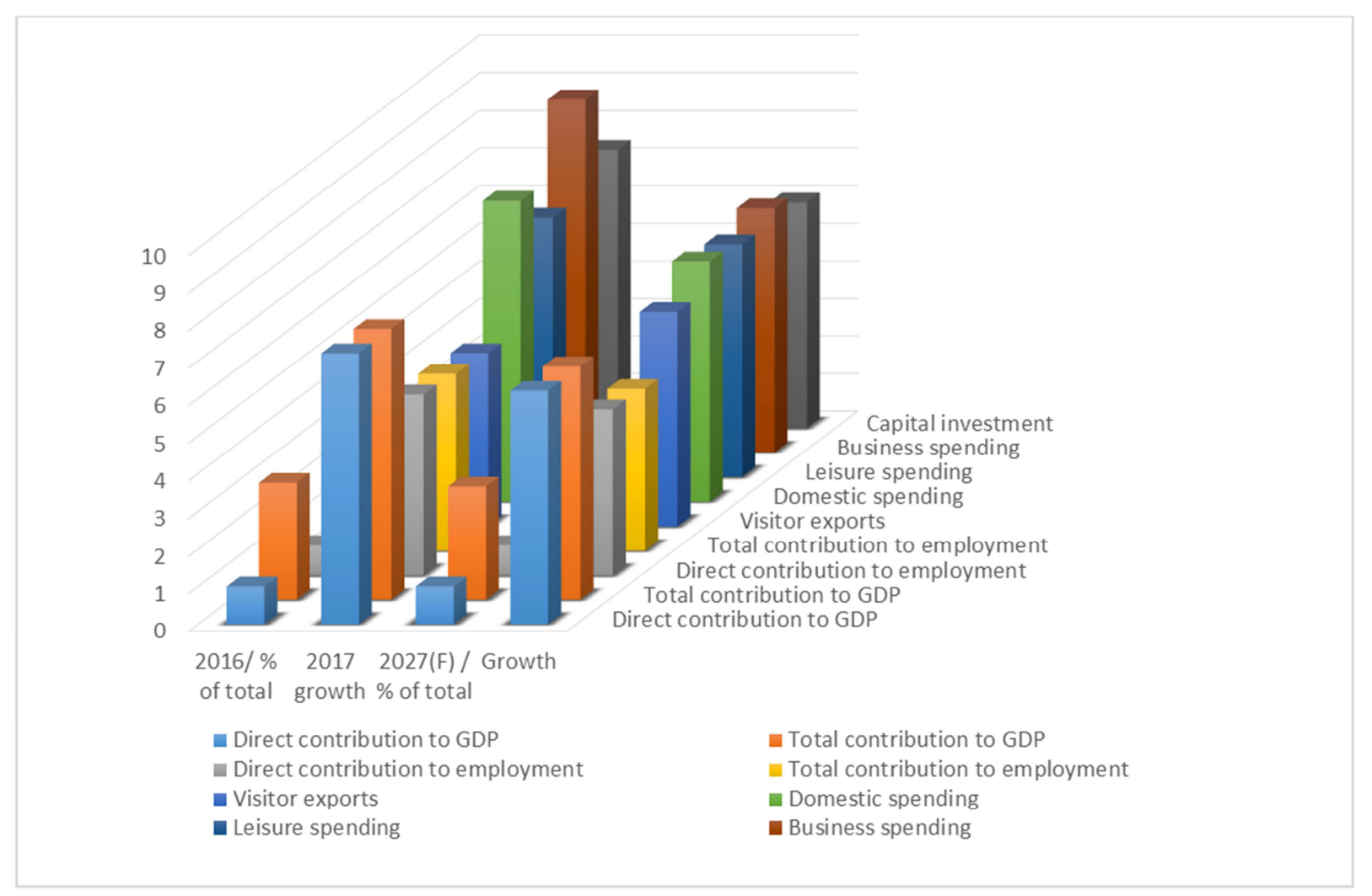

Figure 2. Uzbekistan: estimates \& forecasts [12].

An important aspect of innovation management is the development of innovation infrastructure. Innovative infrastructure - the branche of the economy, scientific and technical knowledge, services, which directly ensure the development of innovative processes in production. It includes a complex of innovative, information, consulting, computing, training and other centers, investment, scientific and technical exchanges, organizational and other services to support all specific stages of innovation activities.

\section{Result and Discussion}

For truly develop any kind of the model in innovation tourism we need to take in to the account wide capacity of the industry. Tourism demand is strongly determined by the "the novelty of attraction." These are found (together or separately) the case of the deals of the following units: the SPA centres, restaurants, cafes, teahouses, treatment structures for care and beauty, entertainment; animation, all deals integrated into the accommodation suppliers [16]. In Uzbekistan the levers of state influence on innovation activity of tourist organizations are:

1. Creation of favorable conditions for attracting domestic and foreign investment in the tourism industry;

2. granting privileges to active organizations and enterprises introducing innovations;

3. Implementation of special scientific and technical, tax and credit and financial policies;
4. Improvement of depreciation policy;

5. Establishment of priority directions for the development of science and technology.

To create an innovative strategy and further implementation of innovative ideas in the field of tourism (automation, software development, development of new types of tourism and new tourist routes, novelties in hospitality services, etc.), an innovation management system that meets the requirements of the industry and the market. The effectiveness of creating a new tourist product, the pace of its development is determined by innovative activity in the production of a new product, which either satisfies a completely new need, or allows expanding the consumer market. These fostering shadow factors, in synthesis, act as in the following model.

The creation and development of new technologies and modern approaches to the management of the tourist business without investing the actual problem can not be solved. Thus, the creation of a favorable investment climate to attract domestic and foreign investment is another problem of the state and business. Attracting investment in the creation and implementation of innovations is a complex process that requires certain skills and experience. For faster and more successful passage of the process of attracting investments, it is necessary to promote professional specialists, consultants and enterprises with experience in attracting financial investments to create innovative projects and products in the tourism industry and related industries. 


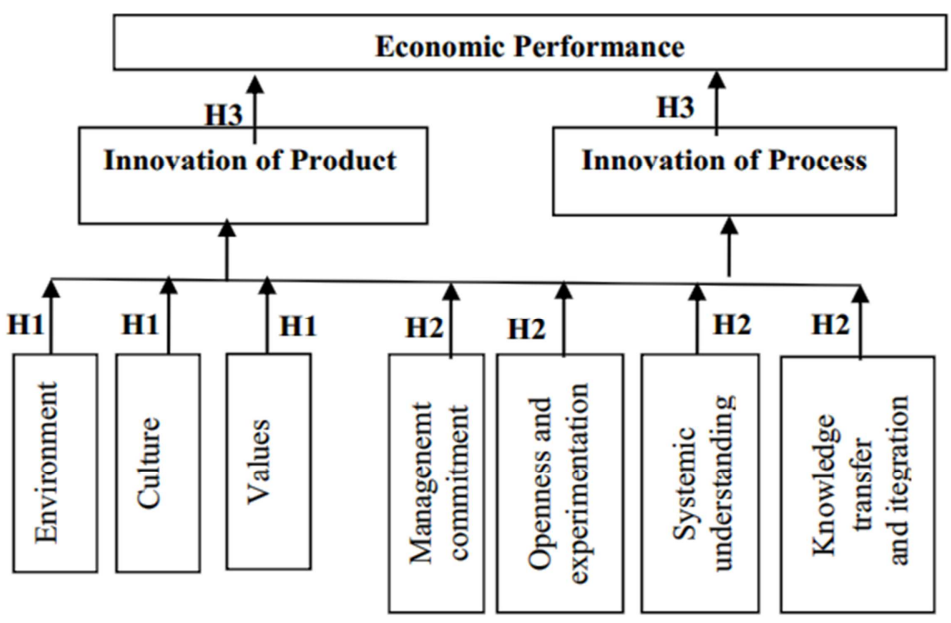

Figure 3. The model of relationship between innovative performance and economic performance of a SME through fostering the shadow factors [7].

\section{Conclusion}

The new tourism is influenced by factors such as demographic changes (aging of the population), lifestyle, the nature of work, the frequency and duration of holidays. People are striving for new and non-standard travel. Their growing awareness, new needs stimulate the tourism business, encourage innovation and innovation. Most innovative tourism products have their niches in the market space (for example, ecological, adventure, extreme tourism). Sustainable popular is cultural and cognitive tourism, in which innovative products have appeared.

Summing up, First of all, introducing the achievements of scientific and technological progress and best practices, innovative innovations in the development of tourism, it will be possible to create new concepts of tourism, tourist services, and implement them in new formats of services. The formation of new approaches and the introduction of innovations in the development and regulation of the tourism sector will make it possible to create an adequate tourist industry with a well-developed material and technical base.

Only in conditions of reliable information on the state it is possible to achieve stable trends in the development of tourism as a whole. Currently, only the initial steps in these areas are traced. Projects of innovative and investment activity in the field of tourism are being developed. It can also be noted that in the conditions of the emerging modern market of tourist services of the country and the region, entrepreneurship will become an important factor and the main form of implementing innovative trends in this market. Based on the studied methodological approaches to the study of innovative management in tourism, described in the local and foreign literature, in our opinion, in order to build an effective methodology for innovative development, it is necessary to evaluate the entire spectrum of indicators related to the service sector, taking into account the traditional and local conditions for the development of a specific tourist destination, and also conduct a comprehensive analysis of the state of tourist resources.

\section{References}

[1] National Legislation Database (www.lex.uz), 6 February 2018, N УП-5326 Decree of the President of the Republic of Uzbekistan "On additional organizational measures to create favorable conditions for the development of the tourism potential of the Republic of Uzbekistan".

[2] Justyna Majewska, Szymon Truskolaski. (2018) Clustermapping procedure for tourism regions based on geostatistics and fuzzy clustering: example of Polish districts. Current Issues in Tourism0:0, pages 1-21.

[3] Keith Debbage. (2018) Economic geographies of tourism: one 'turn' leads to another. Tourism Geographies 20:2, pages 347353.

[4] Sofia Karampela, Dimitris Kavroudakis, Thanasis Kizos. (2017) Agritourism networks: empirical evidence from two case studies in Greece. Current Issues in Tourism 0:0, pages 120.

[5] Justyna Majewska. (2017) GPS-based measurement of geographic spillovers in tourism - example of Polish districts. Tourism Geographies 19:4, pages 612-643.

[6] Irma Booyens, Christian M. Rogerson. (2017) Networking and learning for tourism innovation: evidence from the Western Cape. Tourism Geographies 19:3, pages 340-361.

[7] César Camisón, Beatriz Forés, Montserrat Boronat-Navarro. (2017) Cluster and firm-specific antecedents of organizational innovation. Current Issues in Tourism 20:6, pages 617-646.

[8] Katarzyna Czernek. (2017) Tourism features as determinants of knowledge transfer in the process of tourist cooperation. Current Issues in Tourism 20:2, pages 204-220.

[9] Xiang Ying Mei, Merethe Lerfald, Hans Olav Bråtå. (2017) Networking and collaboration between tourism and agriculture: food tourism experiences along the National Tourist Routes of Norway. Scandinavian Journal of Hospitality and Tourism 17:1, pages 59-75.

[10] Ko Koens, Rhodri Thomas. (2016) "You know that's a ripoff": policies and practices surrounding micro-enterprises and poverty alleviation in South African township tourism. Journal of Sustainable Tourism 24:12, pages 1641-1654. 
[11] "Collection of Legislation of the Republic of Uzbekistan", February 13, 2017, No. 6, article 70 Decree of the President of the Republic of Uzbekistan" On the strategy for further development of the Republic of Uzbekistan "07. 02. $2017 \mathrm{~N}$ UP-4947.

[12] World Travel and Tourism Council: Economic Impact 2017 March 2017, "ECONOMIC IMPACT 2017 UZBEKISTAN" p. 4-6.

[13] Gremyr, I., Witell, L., Löfberg, N., Edvardsson, B. and Fundin, A. (2014), "Understanding new service development and service innovation through innovation modes", Journal of Business \& Industrial Marketing, Vol. 29 No. 2, pp. 123-131.
[14] Sorescu, A., Frambach, R. T., Singh, J., Rangaswamy, A. and Bridges, C. (2011), "Innovations in retail business models", Journal of Retailing, Vol. 87, pp. S3-S16.

[15] Carlborg, P., Kindström, D. and Kowalkowski, C. (2014), "The evolution of service innovation research: a critical review and synthesis", The Service Industries Journal, Vol. 34 No. 5, pp. 373-398.

[16] A. Mirela, E. Aurelia. (2015) "Innovative practices in tourism. Apossible model by fostering shadow factors" ECOFORUM, [Volume 4, Special Issue 1, 2015]. 